\section{Leadership curricula}

\section{ASPECTS OF LEADERSHIP BEST LEARNT AT MEDICAL SCHOOL AND HOW THESE RELATE TO AUSTRALIAN MEDICAL COUNCIL GRADUATE OUTCOMES}

${ }^{1}$ Oscar Lyons*, ${ }^{2}$ Karina McHardy, ${ }^{3}$ Warwick Bagg, ${ }^{4}$ Tim Wilkinson. ${ }^{1}$ University of Oxford, Oxford, UK; ${ }^{2}$ Accident Compensation Corporation, Wellington, New Zealand; ${ }^{3}$ The University of Auckland, Auckland, New Zealand; ${ }^{4}$ The University of Otago, Dunedin, New Zealand

\subsection{6/leader-2018-FMLM.70}

Introduction/background Leadership is a core competency of doctors. However, specific learning outcomes for leadership are not well defined in medical school curricula in New Zealand and Australia.

Aim

1. Define learning outcomes (LOs) for leadership in prequalification medical curricula

2. Evaluate the extent to which Australian Medical Council (AMC) standards meet LOs for medical leadership

Methods After conducting a literature search the UK's Medical Leadership Competency Framework (MLCF) was selected as the 'gold standard' framework.

Each author assessed whether relevant AMC standards sufficiently aligned to each MLCF domain, and consensus was achieved.

Results

1. No clear 1:1 relationship between AMC and MLCF LOs. Many standards were too general or too specific. Significant interpretation of LO intent was required.

2. Many existing AMC outcomes fit within the leadership framework. These could be more explicit.

3. Some key elements of leadership are not yet encapsulated by AMC LOs (e.g. tools for system improvement/audit).

4. Many MLCF competencies could be introduced into medical school curricula as foundations for further development after graduation.

5. Some MLCF competencies are more effectively learnt after graduation.

Conclusions Leadership is multidimensional. Some dimensions may be more appropriately learnt after medical school. There are however significant gaps in current curricula as defined by the AMC, which could be met more effectively using the MLCF guidance.

Discussion MLCF leadership domains are not yet sufficiently aligned to current AMC standards. This suggests further work is required to ensure medical curricula meet the leadership needs of our graduates.

\section{Leadership development}

\section{THE OXFORD FUTURE LEADERS PROGRAMME: A MIXED-METHODS EVALUATION}

'Oscar Lyons*, Richard Canter. University of Oxford, Oxford, UK

10.1136/leader-2018-FMLM.71

Background The Future Leaders Programme (FLP) was a leadership and organisational change training programme for newly appointed consultants at the Oxford University Hospitals NHS Foundation Trust (OUH). It aimed to equip new consultants with skills, knowledge and experience to lead sustainable change, and was centred around quality improvement projects as a vehicle for skill development and a metric of outcomes.

The FLP was developed with blended learning techniques. It consisted of a series of monthly full-day workshops over 12 months with discussions, lectures, workshops, experiential learning, simulation, and mentoring.

Evaluation Evaluation was conducted with a mixed-methods approach based on Kirkpatrick's framework for evaluation of educational outcomes: (Harden, Grant and Buck, 1999; Hammick, Dornan and Steinert, 2010)

- Levels 1 and 2 (Reaction/Learning)

- Questionnaire based on Pendleton and Furnham's Primary Colours model (Pendleton and Furnham, 2016)

- Level 3 (Behavioural Change)

- Post-course questionnaire; interviews

- Level 4 (System)

- QI project outcomes

Results 24 participants completed FLP2, in 6 project teams. $85 \%$ reported working over the allocated 4 hours per week (68\% worked more than 4 hours over) Despite this, $100 \%$ of respondents reported an increase in motivation, 95\% reported an increase in confidence, and $84 \%$ reported an increase in job satisfaction and resilience. $88 \%$ of individual average scores across the Pendleton and Furnham questionnaire reduced over the course. A change in reference frame was indicated by questions regarding knowledge of strategy. 3/6 (50\%) QIP's showed clear improvement and 5/6 (83\%) showed some improvement. Independent financial analysis showed a clear return on investment (ROI) for the course.

Conclusions Despite increased workload associated with a leadership course, these results show that it is possible to generate positive individual, organisational and patient outcomes, with positive ROI.

Further study is needed to investigate factors that influence the success of such programmes, and to investigate reference frame changes that might explain the overall decrease in selfassessed scores shown.

\section{REFERENCES}

1. Hammick M, Dornan T, Steinert Y. Conducting a best evidence systematic review. Part 1: From idea to data coding. BEME Guide No. 13. Medical Teacher 2010;32 (1):3-15. doi:10.3109/01421590903414245

2. Harden R, Grant J, Buck G. BEME Guide No. 1: Best evidence medical education. Medical Teacher 1999;21(6):553-562. doi:10.1080/01421599978960

3. Pendleton D, Furnham A. Leadership?: All You Need To Know 2016.

\section{Enhancing your leadership skills}

\section{LEADERSHIP STRATEGIES FOR ADDRESSING UNPROFESSIONAL BEHAVIOUR IN HEALTHCARE}

${ }^{1}$ Tweedie J*, ${ }^{2}$ Cooper J, ${ }^{3}$ Banerjee J. ${ }^{1}$ Royal College of Physicians/University College London; ${ }^{2}$ Warwick Medical School, Warwick; ${ }^{3}$ University Hospitals of Leicester, Leicester

10.1136/leader-2018-FMLM.72

Unprofessional behaviour occurs when the use of inappropriate words, actions or inactions by a physician interferes with 